\title{
Toward LCA-lite: A Simplified Tool to Easily Apply LCA Logic at the Early Design Stage of Building in Australia
}

\author{
Toktam B. Tabrizi ${ }^{1}$ and Arianna Brambilla ${ }^{1}$
}

\begin{abstract}
Life Cycle Assessment (LCA), developed over 30 years ago, has been helpful in addressing a growing concern about the direct and indirect environmental impact of buildings over their lifetime. However, lack of reliable, available, comparable and consistent information on the life cycle environmental performance of buildings makes it very difficult for architects and engineers to apply this method in the early stages of building design when the most important decisions in relation to a building's environmental impact are made. The LCA quantification method with need of employing complex tools and an enormous amount of data is unfeasible for small or individual building projects. This study discusses the possibility of the development of a tool that allows building designers to more easily apply the logic of LCA at the early design stage. Minimising data requirements and identifying the most effective parameters that promise to make the most difference, are the key points of simplification method. The conventional LCA framework and knowledge-based system are employed through the simplification process. Results of previous LCA studies in Australia are used as the specific knowledge that enable the system to generate outputs based on the user's inputs.
\end{abstract}

Keywords: Life Cycle Assessment (LCA), early design stage, most effective parameters, life cycle environmental performance

\section{Introduction}

At the global level, the building industry is recognised as one of the main contributors to the depletion of natural resources and waste-generation. Buildings affect on the environment through their whole life cycle from extraction of raw materials, construction, operation and end of their life. Moreover, the built environment plays a significant role in air and water pollution, solid waste, deforestation, toxic wastes, health hazards, global warming, and other negative consequences (Bruce-Hyrkäs et al. 2018; Cabeza et al. 2014a; Curran 2014). Energy consumption and the consequent generation of greenhouse gas (GHG) emissions are also significan in buildings, contributing 33\% of the world's emissions (UNEP 2009a; UNEP 2009b). The construction and operation are responsible for most of this impact. Energy consumption and the use of fossil fuel in these processes significantly affect climate change (Koo, Park, Hong, \& Park, 2014). Existing buildings consume more than $40 \%$ of the world's total primary energy and account for $24 \%$ of global carbon dioxide $\left(\mathrm{CO}_{2}\right)$ emissions (IEA, 2008).

Over the past few decades, environmental building performance assessment has become one of the main issues in sustainable construction (Ding 2008; Cole 1999; Crawley and Aho 1999; Rees 1999; Holmes and Hudson 2000). The current concern for architects and engineers worldwide is how to minimise the buildings environmental impact through 
their whole life cycle. Buildings, with the direct and indirect impact on the environment, need to be assessed over their whole lifetime. Therefore, a comprehensive methods such as LCA should be applied (Trusty \& Horst, 2002). LCA is a method for the systematic analysis of environmental impacts of the products or processes over their life cycle. LCA is often considered as a "cradle-to-grave" approach to the evaluation of environmental performance. Cradle-to-grave analysis includes all phases of a product's life: the extraction of raw materials, component's and related materials production, their use and maintenance, and waste removal or recycling (Cabeza et al., 2014).

Generally, the design of a building is an iterative process that drives in several stages from a conceptual level to a detailed one. It moves from the abstract to the specific. The decisions made at the early phases of the building design process significantly affect on building efficiency. As a consequence, minimising buildings life cycle environmental impact and energy consumption are best achieved in the early stages of the design process(Hollberg et al. 2018). The most important decisions for designing an life cycle environmentally friendly building are made in the early stages of building design, yet the very nature of this stage renders such decision-making problematic.

The aim of this study is addressing the following questions:

- Why is the LCA difficult to apply by building designers at the early design stage?

- How to simplify LCA for being applied by designers at the early design stage using the base LCA framework?

Then, the possibility of the development of a tool that allows building designers to easily apply the logic of LCA at the early design stage is discussed.

\section{Why is the LCA Difficult to Apply by Building Designers at the Early Design Stage?}

At the early design stage, a multitude of interrelated parameters affects a buildings LCA that makes it too complex for designers to base decisions on. The difficulty of LCA application at the early design stage is related to various areas. The availability of data in the initial stages of design is a major difficulty for designers. A huge amount of data and a certain degree of expertise in the field are required for the LCA. To accurately perform LCA, building plans, including details of external walls, partitions, slabs, roof, and the selected cladding system, needs to be well defined. Most design decisions at the early design stage are based upon on the designer's experience rather than quantitative indicators due to limited expertise of building designers in LCA. Furthermore, the building form and fabric are fluid at the early design stage. Inventory assessment of building materials and the process of construction and demolition are the main aspects of the environmental impact assessment. However, a major difficulty with this kind of analysis is that the material production processes are not always standardised due to the contextually specific aspects of each building. Designers have limited access to assessable information about the environmental impacts of the production and manufacturing of construction materials plus the actual process of construction and demolition (Ramesh et al. 2012). Moreover, the effective factors on the embodied energy and the equivalent carbon emission of materials and products vary by country due to the energy mix, transformation processes, efficiency of the industrial and economic system 
of the country, and the variability of these factors over time (Sartori \& Hestnes, 2007). One important aspect for decisions made from a life cycle point of view involve ensuring that a solution to reduce environmental impact for one life cycle stage does not increase overall LCEI. Results from previous studies of life cycle energy requirements (Crawford, Czerniakowski, \& Fuller, 2011; Utama \& Gheewala, 2009) demonstrate that a particular material or assembly may perform differently when applied in a different situation. For instance, materials with low initial embodied energy do not necessarily have low life cycle energy. In addition, it is not possible to draw any comparisons among the perivios LCA studies and find generalisable design principles that could be employed by designers at the early design stage. It was identified through the review of some LCA studies of building materials and products due to use of different assumptions, materials, databases and analysis method (Asif, Muneer, \& Kelley, 2007; Bribián, Capilla, \& Usón, 2011; Crawford, 2013; Dodoo, Gustavsson, \& Sathre, 2014; Kofoworola \& Gheewala, 2008; Lee, Kim, \& Na, 2015; Monahan \& Powell, 2011; Monteiro \& Freire, 2012; Thiel et al., 2013).

\section{How to Simplify LCA for Being Applied by Designers at the Early Design Stage Using the Base LCA Framework?}

The quantitative LCA method uses a four-step methodology based on requirements prescribed by ISO 14040 (ISO14040, 2006): goal and scope definition, inventory modelling, impact assessment, and interpretation of results. Every LCA study starts by defining a goal and scope to identify the purposes, audiences and system boundaries. Life cycle inventory (LCI) uses data collection and calculation to calibrate materials and energy inputs and outputs of a system. The potential environmental impacts, based on life cycle modelling, are appraised by impact assessment. This converts the results of LCI into measurable impacts. Impact assessment is responsible for classifying the environmental inputs and outputs for each design scenario according to their impact on the environment. The final step in the LCA methodology combines all the results from the inventory modelling and impact assessment to identify the most important inputs, outputs and environmental impacts while considering the goal and scope. Interpretation determines which results, limitations and recommendations are presented.

To simplify LCA method, each of these steps can play a significant role. By defining the target audiences in Goal and scope, the analyses are limited to provide the essential results for that specific group (e.g. Architects). Various building phases have different impacts on the environment. Although the significant impact of some phases like operational phase has elaborated in most LCA practice, this depends on the specific conditions of each building. For instance, the impact of use phase is very significant in use phase while the maintenance phase is not important for short-life buildings. Defining the system boundary and understanding the relationship between each phase and the specific conditions of each building help designers to make better decisions at the early design stages regarding the building life cycle environmental performance (LCEP). It allows designers prioritise the building heating and cooling needs and select appropriate passive strategies. Inventory modelling with the requirement of the huge amount of data 
that are not available, nor accurate at the early design stage is the most difficult step. In the context of developing a simplified LCA tool, focusing on the most effective building elements can minimize the amount of data required. The importance of the environmental impact indicators could vary in different fields of study. For instance, the impact indicators are different in Agricultural LCAs comparing to buildings' LCAs. Recognising the most relevant factors in terms of a building's environmental impact limits the number of analyses and the data requirements. Interpretation step facilitates ready-to-use results (e.g. Rules of thumb) considering the goal and scope, inventory modelling and the impact indicators.

\section{Methodology}

A qualitative model has underpinned this study's methodology. The multidisciplinary nature of any approach to analysing the LCEP of buildings was the main consideration in the selection of a research model. The process is based on investigation of problems and solutions, exploring and identifing a diversity of perspectives in order to provide explanations, make predictions, interpret and propose solutions. This study discusses the possibility of the development of a tool that allows building designers to more easily apply the logic of LCA at the early design stage. To simplify the LCA to be applied at the early design stage, the initial LCA framework has been applied. An LCALite aims to help architects and building designers to make environmentally friendly decisions at the early design stage. In relation to LCEP, the characteristics of each building will change with changes in its climatic zone, location, building type and building service life. These four criteria are considered as the system boundary. Energy consumption and $\mathrm{CO}_{2}$ emissions have been recognised as the most relevant factors in terms of a building's environmental impact. The environmental impact categories of interest included operational and embodied impacts to educate the LCA-Lite tool. Interpretation as he final step in the LCA framework merges all the results from the LCI and impact assessment to identify the most important inputs, outputs and environmental impacts while considering the goal and scope. This step determines which results, limitations and recommendations are presented. A knowledge-based system has been employed to design a user friendly tool, the LCA-Lite tool, to facilitate interpretation.

\section{Method and Process of Designing a Simplified LCA Tool for Application in the Early Stages of Building Design}

This study presents a method that develops a type of simplified LCA tool for being applied by building designers in the early design stage without application of any complicated software. The simplification process has three main steps:

1) Minimise data requirements by understanding the most effective factors on building LCEP.

2) Define a system boundary to limit the criteria for LCA to the specific condition of every building.

3) Provide some recommendations/rules of thumb for life cycle environmentally friendly design decisions by using available results of previous LCA studies in Australia to make 
connections between each building's condition and effective parameters.

1) The LCEP of buildings should be analysed from different points of view as a building is an integrated system with a long lifetime and complex composition. A simplified way of using LCA is to assess the environmental impact of primary building elements which are the main interface between the internal environment and the external environment. This would significantly minimise buildings LCEP. The building envelope plays a crucial role in the design of life cycle environmentally friendly buildings with the responsibility of more than $50 \%$ of the embodied energy distribution in buildings (COAG, 2009). Several studies (e.g. Granadeiro et al. 2013b; Koo et al., 2014; Sadineni et al. 2011; Ramesh et al. 2011; Mwasha et al. 2011; Cheung et al. 2005) has elaborated the significant impact of a building's envelope on its environmental performance through its lifetime. Different parameters such as orientation, window type, window-to-wall ratio, window location, shading type, wall and roof type, façade typology, envelope materials, thermal insulation, thermal mass, climate and outdoor temperature have been identified in the literature as important impact factors(Cheung et al. 2002; Granadeiro et al., 2013; Koo et al., 2014; Lam et al., 2005; Mwasha et al., 2011; Sadineni et al., 2011; Wan \& Yik, 2004). These parameters, that affect a building's thermal and visual comfort level and its energy demands, are controlled by designers (Oral \& Yilmaz, 2002).

Window system design and effective parameters: Windows are one of the most influential building's elements regarding a building's LCEP (Huang et al. 2014; Cuce and Riffat 2015; Amaral et al. 2016; Sun 2017; Sun et al. 2018). Window's orientation, dimensions and shading affect the optimisation energy consumption and thermal comfort. Building energy efficiency is greatly affected by the glazed area which is responsible for up to $60 \%$ of heat loss through the fabric in residential buildings (Lee et al. 2013; Goia 2016; Kirimtat et al. 2016; Jelle et al. 2012). Passive solar gain, ventilation, day-lighting and vision are the building's needs that are responded by window design. Reviewing the LCA studies of window system led this research to select the following parameters as the most effective indicators of window system on minimising buildings environmental impact through their whole life cycle: Window to Wall Ratio (WWR); Glazing type Frame type; Shading (Amaral et al., 2016; Cheung et al., 2002; Goia, 2016; Nedhal Al-Tamimi, 2012; Radhi \& Sharples, 2013; Su \& Zhang, 2010; Yang et al., 2015; Citherlet et al., 2000; Eskin \& Türkmen, 2008; Lee et al., 2013; Switala-Elmhurst, 2014; Weir \& Muneer, 1998; Asif et al., 2002; Salazar \& Sowlati, 2008; Babaizadeh et al., 2015).

Solid envelope design and effective parameters: The choice of solid envelope materials and assemblies are one of the main responsible for buildings energy demands for use, maintenance, initial and recurrent embodied energy and the energy used in demolition and disposal of materials. As the skin of buildings, they particularly influence on the heating and cooling load of a building (Crawford et al., 2011). Material selection and design strategies for different layers of opaque envelope like external cladding, insulation, frame and internal lining are considered to be effective indicators for the building's LCEP. (Basbagill et al., 2013; Cheung et al., 2002; Himpe et al., 2013; Iddon \& Firth, 2013; Nedhal Al-Tamimi, 2012; Ramesh, Prakash, \& Shukla, 2012; Rauf \& Crawford, 2013).

2) Defining a system boundary helps minimising LCA data requirements at the early design stages. Building designers at the early design stage of each project have access to detailed information about the climate, location and type of the building. Moreover, they 
are able to make reasonably reliable assumptions about the building lifetime (in some cases this is decided by the building code). These four factors were identified as the most effective external criteria in the LCA of a building. Accordingly, the following four external criteria were selected to define the system boundary for simplifying the LCA process at the early design stage of buildings.

Climate plays the main role in building energy efficiency performance and regulations around the world. It directly affects annual heating and cooling energy loads with a huge impact on a building's operational phase and the whole building's LCEP. Climate has been considered to be one of the most effective external criteria in building LCEP in most previous studies. It is even more important in extreme weather conditions. For example, the results from a review of office building strategies showed significant differences between hot and cold climates (Crawford et al., 2016; Ochoa \& Capeluto, 2008).

Location is an influential factor in a building's LCEP in relation to both operational and embodied energy demands. The country and geographic region which are factors that have different impact on LCA compared to climate. Policies and technological improvements in developed countries over recent years have shifted the ratio of operational versus embodied energy towards an increasing share of the latter (Koezjakov et al. 2018; Lützkendorf et al. 2015; Sorrell 2007). Location has considered as an important factor in analysing buildings embodied energy (Chen et al., 2001; Koezjakov et al. 2018; UrgeVorsatz et al., 2018; Meijer et al., 2009). Crawford et al. (2011) used location as an effective factor to rank different envelope assemblies. Requirement for air conditioning, usual operating hours and the typical fuel mix used to supply energy for heating and cooling vary considering different country and geographic region of each building. Shading system, with the significant impact on the operational energy, is directly affected by the location latitude, sun position and sky clarity. Different manufacturing practices, energy consumption patterns, transportation and logistical systems, electricity generation and distribution in different geographic locations and local macro climates affect buildings LCEP (Azari et al. 2016). In addition, environmentally friendly design should always meet the legislative requirements of the construction location, which vary from one region to another. Bambrook et al. (2011), for example, considered the BASIX energy efficiency requirement of New South Wales when analysing the optimal performance of insulation thickness of the walls and roof, window type, the thickness of an internal thermal mass wall, and the air change rate during night ventilation. The location of the manufacturing sources is very important in LCI analysis. The use of an LCA database from different manufacturing sources (e.g. Switzerland, Europe, USA, North America, France) affects the embodied energy of construction materials or components (Martínez-Rocamora et al. 2016).

Building type is one of the key factors in analysing a building operation phase in relation to heating, cooling, lighting and electricity for appliances. The importance of operational parameters varies in different building types. For instance, space heating and cooling are the main consideration in residential building energy demands in harsh climates while lighting energy demand is a significant factor in the envelope design of an office building in terms of minimising its environmental impact (Ochoa and Capeluto 2008). Operating patterns and the use of air conditioning, operating schedules following by operational energy consumption via thermostat settings, floor usage and the type of activity in different spaces are main factors related to building type that affect LCA results (Attia et 
al. 2012; Azar and Menassa 2014; Heeren et al. 2015; Lin et al. 2018; ASHRAE 2013; Lin et al. 2018; Azar et al. 2016). Building use is one of the influential factors on a building's thermal scope, along with location, materials and energy supply (Østergaard et al. 2018). Material selection considering the requirements of different building types should not have an adverse impact on the environment. Operation and maintenance, as the main responsible phases, that has different impact in different types of buildings due to the building's function, operational hours and occupants. Moreover, material quantity and type to satisfy building design requirements according to its function, have an impact on the demolition phase (Mastrucci et al. 2017). Energy regulations and energy rating also differ for different types of buildings (Dotzler et al. 2018).

Building lifetime is important to be considered in LCA as some building materials and components need to be maintained or replaced over a building's lifetime. The service life of the building and its materials affect its recurrent embodied energy and carbon (Seo et al. 2018). The environmental impact of material service life, material reusability and recyclability varies with changes in the building's lifetime. Seo et al. (2018) indicates that materials with longer service life minimise the buildings' LCEP but this only applies the buildings with long lifetimes. Another study (Østergaard et al. 2018) considers the role of a building's service life in LCA in terms of its thermal scope besides other factors such as building location, choice of materials, energy supply and building function. An inaccurate estimation of building's service life significantly impacted on the results of building LCEP. The importance of considering building lifetime in LCA is highlighted by Cabeza et al. (2014) in a comprehensive review of studies on the LCA of buildings and building sectors.

3) Extracting common rules from the results of previous LCA studies can be used as a strategy for simplifying the LCA process. The LCA results of case studies in the literature can provide a broad range of data in terms of the impact of envelope design variables on the environment and optimal solutions. However, generalising the heuristic elementary principles for application to new projects is not easily possible for a number of reasons, namely: the specific character of each project; different goals and scope; use of different LCI databases; the use of different methods and phases in their analyses; different assumptions, estimations and interpretations. Extracting common rules and provide some general recommendations for designers within certain limitations and by focusing on specific criteria can be a solution to this issue. However, application of these common rules is still difficult at the early design stage of building regarding the unique factors associated with each project (e.g. climate). A method is needed to specify common rules regarding the relationship between these criteria and the external condition of every building.

\section{The Simplified Tool Structure}

A Knowledge-based System (KBS) has applied in this study for designing the LCA-Lite Tool. KBS is a computer system that uses various levels of Artificial Intelligence (AI) for problem solving in different domains. It includes a database of expert knowledge that is designed to be used for specific queries, along with learning and justifications. It provides data and information as the knowledge from various sources. It is a system used for supporting human decision-making by employment of knowledgebased techniques. The main capability of KBS is cooperation with human users for 
problem solving, training, and assisting experts and users in the domain for which the system was designed and developed. The process used to design the user-friendly tool and its technical descriptions are presented in this section. The tool is designed in three main parts: inputs, system functions and outputs. It is designed to generate information in connection with each specific group of input data using the defied rules.

Input: Developing a streamlined LCA methodology requires the consideration of specific aspects such as being easy to find in the building project and be available at the early stages of the design process with an acceptable level of certainty. Inputting the essential information about the building is the first step of investigating the most effective parameters on building LCEP. The level of effectiveness of each parameter is defined by the specific condition of each building. Making this connection can significantly reduce the data requirements for the LCA. Designers input the essential data by selecting among the Climate, Location, Building type and Building lifetime subsets (Table 1).

Table 1: Input data based on specific characteristics of the building in Australia

\begin{tabular}{l|l} 
& $\begin{array}{l}\text { Climate zone 1 - High humid summer, warm winter } \\
\text { Climate zone 2 - Warm humid summer, mild winter } \\
\text { Climate zone 3 - Hot dry summer, warm winter } \\
\text { Climate zone 4 - Hot dry summer, cool winter } \\
\text { Climate zone 5 - Warm temperate } \\
\text { Climate zone 6 - Mild temperate } \\
\text { Climate zone 7 - Cool temperate } \\
\text { Climate zone 8 - Alpine }\end{array}$ \\
\hline \begin{tabular}{l|l} 
New south wales (Sydney) \\
Queensland (Brisbane) \\
South Australia (Adelaide) \\
Tasmania (Hobart) \\
Victoria (Melbourne) \\
Western Australia (Perth)
\end{tabular} \\
\hline $\begin{array}{l}\text { Residential } \\
\text { Office }\end{array}$ \\
\hline $\begin{array}{l}\text { Short (any temporary construction with service life of less than 10-15 years) } \\
\text { Average (service life of around 50 years which is the common assumption used in } \\
\text { most LCA studies) } \\
\text { Long (buildings with service life of more than 75 years) }\end{array}$
\end{tabular}

System function: A basic tool designed using the knowledge-based system which contains the specific knowledge in the form of rules. It enables the system to generate outputs based on the user's inputs. The target knowledge for collection of data (data acquisition) helps designers to make better environmentally friendly decisions at the early stages of building design with minimum time, effort and cost which is the aim of the tool. Transparent and opaque elements of building envelope with the most impact on a building's LCEP structure the database for the purpose of designing the tool. The following two groups of factors are considered in this study as the most effective for building environmental performance over the various phases of the building's lifetime (Table 2). The knowledge of the tool, using the results of related LCA studies in Australia, is built based on the 
relationship between the most effective factors from a building envelope and the external criteria (climate, location, building type and building lifetime). Each one contains a number of recommendations for designers in order to minimise the buildings LCEP. The inference engine uses the information from the knowledge to derive the conclusion. The results from quantitative LCA (in the form of extracted rules) provide a ready to use and reliable database for structuring the qualitatively-based design LCA. They provide the required common rules without the need for complex analyses. Although this method is not comprehensive or highly accurate, it has the potential to fulfill the designer's needs at the early stages of the building design process (Discussing the method of generating data for the system is not within the scope of this paper).

Outputs: The system outputs are responsible for making a foundation for thinking through problems and understanding that a building is a complex product that moves from cradle to grave. A small number of recommendations for design and material selection decisions for the building's envelope structure the outputs of the tool. These are expected to minimise the building's life cycle environmental impact. These recommendations are based on the specific condition of each building which the user inputs into the system as the first step and are generated in two groups, one for window design and the other for solid envelope design.

Table 2: Two groups of most effective factors on the buildings LCEP

\begin{tabular}{c|c}
$\begin{array}{c}\text { Window-related factors } \\
\text { (Transparent elements) }\end{array}$ & $\begin{array}{c}\text { Envelope-related factors } \\
\text { (Opaque elements) }\end{array}$ \\
\hline WWR & Cladding \\
Glazing type & Insulation \\
Frame type & Frame \\
Shading & Lining
\end{tabular}

\section{Small Demonstration Case Study of the LCA-Lite Tool in Action}

A medium sized multi-storey residential building in Sydney with assumed 50 year lifetime is selected here as a hypothetical case study. Inputs to the LCA-Lite tool are the specific condition of the building in Australia which the inference engine uses this information and makes connection between these and the defined database to derive the conclusion. All envelope-related design considerations in order to reduce a building environmental impact considers as the database. The outputs are the result of the tool's interpretation based on the input data. Therefore, the tool's output provides two groups of recommendations, one for the windows and one for the solid envelope (Figure 1). It shows how the LCA-Lte tool provides designers some rules of thumb and general recommendations to become aware of the most influential factors on the building's LCEP. Each part shows a list of design considerations that building designers should take into account at the early stages of the design process to minimise a building life cycle environmental impact. The specific condition of the building project, as input data, helps the system to generate more details as outputs. It is a primary mock-up of the application of the designed method in this study. The limitations and possible improvements to the method towards a more comprehensive version are discussed in future studies. 


\section{Conclusions}

Buildings dramatically perform more environmentally friendly among their lifetime if designers can more effectively apply currently available LCA tools at the early design stages. Previous studies have shown that architects and engineers are increasingly aware that their design decisions at the early stages of building design impact on the building's LCEP. Investigating the most effective factors for improving buildings LCEP at the early design phase using current LCA tools is beyond the capacity of most small to medium projects worldwide due to the requirement of considerable amounts of time, cost and expertise. The need for a quick early analysis has not been aim of the existing LCA tools. The method for developing the LCA-Lite tool proposed in this study aims to overcome the reluctance of building designers to use LCA because of its complexity and the difficulties in understanding and applying the results. Small to medium sized buildings which are designed by individual architects are the main targets of LCA-Lite tool. Currently, building designers are not able to perform complicated assessments to understand the most effective factors on the building's LCEP due to their limited budgets, time and expertise. The outputs identifies which environmental dimensions are positively or negatively affected and supports design decisions at the early stages of building design. The LCA-Lite tool highlights the strengths and weaknesses of alternative design strategies and material selections for optimising environmental performance along multiple environmental dimensions while considering each building's condition.

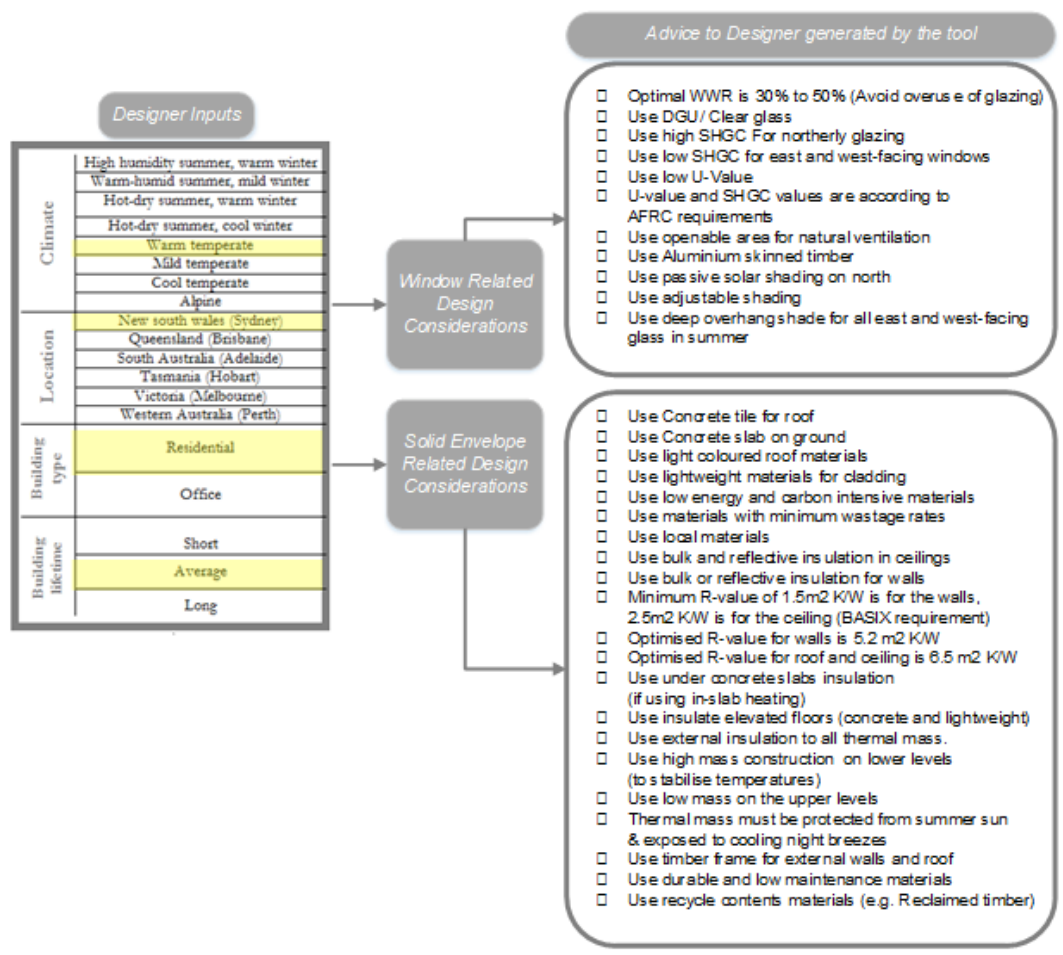

Figure 1: Inputs and outputs of the tool for a bypothetical case study in Sydney 


\section{References}

Amaral, A. R., Rodrigues, E., Gaspar, A. R., \& Gomes, Á. (2016). A thermal performance parametric study of window type, orientation, size and shadowing effect. Sustainable Cities and Society, 26, 456-465. doi:10.1016/j.scs.2016.05.014

Asif, M., Davidson, A., \& Muneer, T. (2002). Life Cycle of Window Materials - A Comparative assessment. School of Engineering, Napier University, 10 Colinton Road, Edinburgh EH10 5DT, U.K.

Asif, M., Muneer, T., \& Kelley, R. (2007). Life cycle assessment: A case study of a dwelling home in Scotland. Building and Environment, 42(3), 1391-1394. doi:http://dx.doi.org/10.1016/j.buildenv.2005.11.023

Azari, R., Garshasbi, S., Amini, P., Rashed-Ali, H., \& Mohammadi, Y. (2016). Multi-objective optimization of building envelope design for life cycle environmental performance. Energy and Buildings, 126, 524-534. doi:10.1016/j.enbuild.2016.05.054

Babaizadeh, H., Haghighi, N., Asadi, S., Broun, R., \& Riley, D. (2015). Life cycle assessment of exterior window shadings in residential buildings in different climate zones. Building and Environment, 90(0), 168-177. doi:http://dx.doi.org/10.1016/j.buildenv.2015.03.038

Bambrook, S. M., Sproul, A. B., \& Jacob, D. (2011). Design optimisation for a low energy home in Sydney. Energy and Buildings, 43(7), 1702-1711. doi:http://dx.doi.org/10.1016/j.enbuild.2011.03.013

Basbagill, J., Flager, F., Lepech, M., \& Fischer, M. (2013). Application of life-cycle assessment to early stage building design for reduced embodied environmental impacts. Building and Environment, 60(0), 81-92. doi:http://dx.doi.org/10.1016/j.buildenv.2012.11.009

Bribián, I. Z., Capilla, A. V., \& Usón, A. A. (2011). Life cycle assessment of building materials: Comparative analysis of energy and environmental impacts and evaluation of the eco-efficiency improvement potential. Building and Environment, 46(5), 1133-1140. doi:http://dx.doi.org/10.1016/j.buildenv.2010.12.002

Bruce-Hyrkäs, T., Pasanen, P., \& Castro, R. (2018). Overview of Whole Building Life-Cycle Assessment for Green Building Certification and Ecodesign through Industry Surveys and Interviews. Procedia CIRP, 69, 178-183. doi:https://doi.org/10.1016/i.procir.2017.11.127

Cabeza, L. F., Rincón, L., Vilariño, V., Pérez, G., \& Castell, A. (2014a). Life cycle assessment (LCA) and life cycle energy analysis (LCEA) of buildings and the building sector: A review. Renewable and Sustainable Energy Reviews, 29(0), 394-416. doi:http://dx.doi.org/10.1016/j.rser.2013.08.037

Carlisle, S., \& Friedlander, E. (2016). The influence of durability and recycling on life cycle impacts of window frame assemblies. International Journal of Life Cycle Assessment, 21(11), 1645-1657. doi:10.1007/s11367016-1093-x

Chen, T. Y., Burnett, J., \& Chau, C. K. (2001). Analysis of embodied energy use in the residential building of Hong Kong. Energy, 26(4), 323-340. doi:http://dx.doi.org/10.1016/S0360-5442(01)00006-8

Cheung, C. K., Fuller, R. J., \& Luther, M. B. (2005). Energy-efficient envelope design for high-rise apartments. Energy and Buildings, 37(1), 37-48. doi:http://dx.doi.org/10.1016/j.enbuild.2004.05.002

Cheung, C. K., Luther, M., \& Fuller, R. J. (2002). Low-Energy Strategies for High-Rise Apartments in Hong Kong. Paper presented at the Australian and New Zealand Architectural Science Association Conference.

Citherlet, S., Di Guglielmo, F., \& Gay, J.-B. (2000). Window and advanced glazing systems life cycle assessment. Energy \& Buildings, 32(3), 225-234. doi:10.1016/S0378-7788(98)00073-5

COAG. (2009). National Strategy on Energy Efficiency, Council of Australian Governments, Canberra.

Cole, R. J., \& Kernan, P. C. (1996). Life-cycle energy use in office buildings. Building and Environment, 31(4), 307-317. doi:https://doi.org/10.1016/0360-1323(96)00017-0

Crawford, R. H. (2013). Post-occupancy life cycle energy assessment of a residential building in Australia. Architectural Science Review, 57(2), 114-124. doi:10.1080/00038628.2013.819556

Crawford, R. H., Bartak, E. L., Stephan, A., \& Jensen, C. A. (2016). Evaluating the life cycle energy benefits of energy efficiency regulations for buildings. Renewable and Sustainable Energy Reviews, 63, 435-451. doi:10.1016/j.rser.2016.05.061

Crawford, R. H., Czerniakowski, I., \& Fuller, R. J. (2011). A comprehensive model for streamlining low-energy building $\begin{array}{llll}\text { design. } & \text { Energy }\end{array}$ doi:http://dx.doi.org/10.1016/i.enbuild.2011.03.020

Crawley, D., \& Aho, I. (1999). Building environmental assessment methods: Applications and development trends (Vol. 27). 
Cuce, E., \& Riffat, S. B. (2015). A state-of-the-art review on innovative glazing technologies. Renewable and Sustainable Energy Reviews, 41(Supplement $\quad$ C), 695-714. doi:https://doi.org/10.1016/i.rser.2014.08.084

Curran, M. A. (2014). Strengths and Limitations of Life Cycle Assessment. In: Klöpffer W. (eds) Background and Future Prospects in Life Cycle Assessment. LCA Compendium - The Complete World of Life Cycle Assessment. Springer, Dordrecht.

Ding, G. K. C. (2008). Sustainable construction - The role of environmental assessment tools. Journal of Environmental Management, 86(3), 451-464. doi:http://dx.doi.org/10.1016/i.jenvman.2006.12.025

Dodoo, A., Gustavsson, L., \& Sathre, R. (2014). Lifecycle primary energy analysis of low-energy timber building systems for multi-storey residential buildings. Energy and Buildings, 81(0), 84-97. doi:http://dx.doi.org/10.1016/i.enbuild.2014.06.003

Eskin, N., \& Türkmen, H. (2008). Analysis of annual beating and cooling energy requirements for office buildings in different climates in Turkey. Energy and Buildings, 40(5), 763-773. doi:http://dx.doi.org/10.1016/i.enbuild.2007.05.008

Goia, F. (2016). Search for the optimal window-to-wall ratio in office buildings in different European climates and the implications on total energy saving potential. Solar Energy, 132, 467-492. doi:10.1016/j.solener.2016.03.031

Granadeiro, V., Correia, J. R., Leal, V. M. S., \& Duarte, J. P. (2013). Envelope-related energy demand: A design indicator of energy performance for residential buildings in early design stages. Energy and Buildings, 61, 215223. doi:10.1016/j.enbuild.2013.02.018

Himpe, E., Trappers, L., Debacker, W., Delghust, M., Laverge, J., Janssens, A., Van Holm, M. (2013). Life cycle energy analysis of a zero-energy house. Building Research and Information, 41(4), 435-449.

Hollberg, A., Lichtenheld, T., Klüber, N., \& Ruth, J. (2018). Parametric real-time energy analysis in early design stages: a method for residential buildings in Germany. Energy, Ecology and Environment, 3(1), 13-23. doi:10.1007/s40974-017-0056-9

Holmes, J., \& Hudson, G. (2000). An evaluation of the objectives of the BREEAM scheme for offices: a local case study. Paper presented at the Cutting Edge 2000, RICS Research Foundation, RICS, London.

Huang, X., Zhang, L., \& Zhu, T. (2014). Building Change Detection From Multitemporal High-Resolution Remotely Sensed Images Based on a Morphological Building Index. IEEE Journal of Selected Topics in Applied Earth Observations and Remote Sensing, 7(1), 105-115. doi:10.1109/JSTARS.2013.2252423

Iddon, C. R., \& Firth, S. K. (2013). Embodied and operational energy for new-build housing: A case study of construction methods in the UK. Energy and Buildings, 67, 479-488. doi:10.1016/j.enbuild.2013.08.041

IEA. (2008). Internatioanal Energy Agency, World Energy Outlook.

ISO14040. (2006). 14040: Environmental management-life cycle assessment-principles and framework. London: British Standards Institution.

Jelle, B. P., Hynd, A., Gustavsen, A., Arasteh, D., Goudey, H., \& Hart, R. (2012). Fenestration of today and tomorrow: A state-of-the-art review and future research opportunities. Solar Energy Materials and Solar Cells, 96(Supplement C), 1-28. doi:https://doi.org/10.1016/j.solmat.2011.08.010

Kirimtat, A., Koyunbaba, B. K., Chatzikonstantinou, I., \& Sariyildiz, S. (2016). Review of simulation modeling for shading devices in buildings. Renewable and Sustainable Energy Reviews, 53, 23-49. doi:10.1016/j.rser.2015.08.020

Klöpffer, W. (2014). Background and future prospects in life cycle assessment [electronic resource]. Dordrecht: Springer.

Koezjakov, A., Urge-Vorsatz, D., Crijns-Graus, W., \& van den Broek, M. (2018). The relationship between operational energy demand and embodied energy in Dutch residential buildings. Energy and Buildings, 165, 233-245. doi:10.1016/j.enbuild.2018.01.036

Kofoworola, O. F., \& Gheewala, S. H. (2008). Environmental life cycle assessment of a commercial office building in Thailand. The International Journal of Life Cycle Assessment, 13(6), 498. doi:10.1007/s11367-0080012-1

Koo, C., Park, S., Hong, T., \& Park, H. S. (2014). An estimation model for the heating and cooling demand of a residential building with a different envelope design using the finite element method. Applied Energy, 115, 205215. doi:10.1016/j.apenergy.2013.11.014

Lam, J. C., Tsang, C. L., Li, D. H. W., \& Cheung, S. O. (2005). Residential building envelope heat gain and cooling energy requirements. Energy, 30(7), 933-951. doi:http://dx.doi.org/10.1016/j.energy.2004.07.001 
Lee, J. W., Jung, H. J., Park, J. Y., Lee, J. B., \& Yoon, Y. (2013). Optimization of building window system in Asian regions by analyzing solar heat gain and dayligbting elements. Renewable Energy, 50(0), 522-531. doi:http://dx.doi.org/10.1016/j.renene.2012.07.029

Lee, S., Kim, S., \& Na, Y. (2015). Comparative analysis of energy related performance and construction cost of the external walls in bigh-rise residential buildings. Energy and Buildings, 99(0), 67-74. doi:http://dx.doi.org/10.1016/i.enbuild.2015.03.058

Lützkendorf, T., Foliente, G., Balouktsi, M., \& Wiberg, A. H. (2015). Net-zero buildings: incorporating embodied impacts. Building Research \& Information, 43(1), 62-81. doi:10.1080/09613218.2014.935575

Martínez-Rocamora, A., Solís-Guzmán, J., \& Marrero, M. (2016). LCA databases focused on construction materials: A review. Renewable and Sustainable Energy Reviews, 58, 565-573. doi:10.1016/j.rser.2015.12.243

Meijer, F., Itard, L., \& Sunikka-Blank, M. (2009). Comparing European residential building stocks: performance, renovation and policy opportunities. Building Research \& Information, 37(5-6), 533-551. doi:10.1080/09613210903189376

Monahan, J., \& Powell, J. C. (2011). An embodied carbon and energy analysis of modern methods of construction in housing: A case study using a lifecycle assessment framework. Energy and Buildings, 43(1), 179-188. doi:http://dx.doi.org/10.1016/i.enbuild.2010.09.005

Monteiro, H., \& Freire, F. (2012). Life-cycle assessment of a house with alternative exterior walls: Comparison of three impact assessment methods. Energy and Buildings, 47(0), 572-583. doi:http://dx.doi.org/10.1016/j.enbuild.2011.12.032

Mwasha, A., Williams, R. G., \& Iwaro, J. (2011). Modeling the performance of residential building envelope: The role of sustainable energy performance indicators. Energy and Buildings, 43(9), 2108-2117. doi:10.1016/j.enbuild.2011.04.013

Nedhal Al-Tamimi, S. F. S. F. (2012). Energy-efficient envelope design for high-rise residential buildings in Malaysia. Architectural Science Review, 55, 119-127. doi:10.1080/00038628.2012.667938

Ochoa, C. E., \& Capeluto, I. G. (2008). Strategic decision-making for intelligent buildings: Comparative impact of passive design strategies and active features in a hot climate. Building and Environment, 43(11), 1829-1839. doi:https://doi.org/10.1016/j.buildenv.2007.10.018

Oral, G. K., \& Yilmaz, Z. (2002). The limit U values for building envelope related to building form in temperate and cold climatic zones. Building and Environment, 37(11), 1173-1180. doi:http://dx.doi.org/10.1016/S03601323(01)00102-0

Radhi, H., \& Sharples, S. (2013). Global warming implications of facade parameters: A life cycle assessment of residential buildings in Babrain. Environmental Impact Assessment Review, 38, 99-108.

Ramesh, T., Prakash, R., \& Shukla, K. K. (2011). Life cycle energy analysis of a residential building with different envelopes and climates in Indian context. Applied Energy, 89(1), 193-202. doi:http://dx.doi.org/10.1016/j.apenergy.2011.05.054

Ramesh, T., Prakash, R., \& Shukla, K. K. (2012). Life cycle approach in evaluating energy performance of residential buildings in Indian context. Energy and Buildings, 54, 259-265. doi:10.1016/j.enbuild.2012.07.016

Rauf, A., \& Crawford, R. H. (2013). The relationship between material service life and the life cycle energy of contemporary residential buildings in Australia. Architectural Science Review, 56(3), 252-261.

Sadineni, S. B., Madala, S., \& Boehm, R. F. (2011). Passive building energy savings: A review of building envelope components. Renewable and Sustainable Energy Reviews, 15(8), 3617-3631. doi:10.1016/j.rser.2011.07.014

Salazar, J., \& Sowlati, T. (2008). A review of life-cycle assessment of windows.

Sartori, I., \& Hestnes, A. G. (2007). Energy use in the life cycle of conventional and low-energy buildings: A review article. Energy and Buildings, 39(3), 249-257. doi:10.1016/j.enbuild.2006.07.001

Sorrell, S. (2007). The Rebound effect: an assessment of the evidence for economy-wide energy savings from improved energy efficiency. Retrieved from UK:

Su, X., \& Zhang, X. (2010). Environmental performance optimization of window-wall ratio for different window type in hot summer and cold winter zone in China based on life cycle assessment. Energy and Buildings, 42(2), 198-202. doi:http://dx.doi.org/10.1016/i.enbuild.2009.08.015

Sun, Y. (2017). Glazing system with Transparent Insulation: Material for Building Energy Saving and Daylight Comfort. (Doctor of Philosophy), The University of Nottingham.

Sun, Y., Wu, Y., \& Wilson, R. (2018). A review of thermal and optical characterisation of complex window systems and their building performance prediction. Applied Energy, 222, 729-747. doi:https://doi.org/10.1016/j.apenergy.2018.03.144 
Switala-Elmhurst, K. (2014). Life cycle assessment of residential windows: Analyzing the environmental impact of window restoration versus window replacement. Paper presented at the Temple University Graduate Board.

Thiel, C. L., Campion, N., Landis, A. E., Jones, A. K., Schaefer, L. A., \& Bilec, M. M. (2013). A materials life cycle assessment of a net-zero energy building. Energies, 6(2), 1125-1141. doi:10.3390/en6021125

Trusty, W., \& Horst, S. (2002). Integrating LCA tools in green building rating systems. Paper presented at the USGBC Greenbuilding International Conference and Expo.

UNEP. (2009a). Buildings and Climate Change: Summary for Decision-makers. Retrieved from

UNEP. (2009b). Common Carbon Metric for Measuring Energy Use and Reporting Greenhouse Gas Emissions from Building Operations. Retrieved from

Utama, A., \& Gheewala, S. H. (2009). Indonesian residential high rise buildings: A life cycle energy assessment. Energy and Buildings, 41(11), 1263-1268. doi:http://dx.doi.org/10.1016/i.enbuild.2009.07.025

Wan, K. S. Y., \& Yik, F. W. H. (2004). Building design and energy end-use characteristics of bigh-rise residential buildings in Hong Kong. Applied Energy, 78(1), 19-36. doi:http://dx.doi.org/10.1016/S0306-2619(03)00103$\underline{X}$

Weir, G., \& Muneer, T. (1998). Energy and environmental impact analysis of double-glazed windows. Energy Conversion and Management, 39(3), 243-256. doi:10.1016/S0196-8904(96)00191-4

Yang, Q., Liu, M., Shu, C., Mmereki, D., Uzzal Hossain, M., \& Zhan, X. (2015). Impact Analysis of WindowWall Ratio on Heating and Cooling Energy Consumption of Residential Buildings in Hot Summer and Cold Winter Zone in China. Journal of Engineering, 2015, 17. doi:10.1155/2015/538254 